\title{
Epigenetic regulation of proMMP-1 expression in the HT1080 human fibrosarcoma cell line
}

\author{
MATHILDE POPLINEAU, JEAN DUFER, FRANK ANTONICELLI and AURELIE TRUSSARDI-REGNIER \\ Unité MEDyC, UMR URCA-CNRS 6237, IFR53, Facultés de Pharmacie et de Médecine, \\ Université de Reims, 1 avenue du Maréchal Juin, 51096 Reims, France
}

Received December 2, 2010; Accepted January 28, 2011

DOI: 10.3892/ijo.2011.975

\begin{abstract}
The matrix metalloproteinase (MMP) family members play an important role in various physiological and pathological processes. Although MMP-1 (collagenase-1) has been shown to be involved in tumor invasiveness, the regulation of its expression is still not fully elucidated and could implicate epigenetic mechanisms. The aim of this study was to analyze the effects of the Histone Deacetylase Inhibitor (HDI) trichostatin A (TSA) and the inhibitor of DNA methylation 5-aza-2'-deoxycytidine (5-azadC) on the proMMP-1 expression in the human HT1080 fibrosarcoma cell line. Real-time RT-PCR revealed that 5 -azadC or 5 -azadC + TSA but not TSA alone, despite global histone H4 hyperacetylation, increased proMMP-1 mRNA levels. This transcription activation was correlated with chromatin decondensation determined by nuclear texture image analysis technique. Western blot analysis of cell culture conditioned media revealed a significant increase in proMMP-1 secretion after 5-azadC or 5-azadC + TSA treatment compared to untreated cells. These results suggested that epigenetic mechanisms could be involved in proMMP-1 gene expression including chromatin supra-organization changes. Indeed, although the proMMP-1 gene promoter does not appear to contain $\mathrm{CpG}$ islands, its expression can be induced by the demethylating agent 5-azadC. Further experiments revealed that inhibition of protein neosynthesis by cycloheximide decreased 5-azadC-induced proMMP-1 mRNA, suggesting that epigenetically regulated intermediate molecules could be involved in proMMP-1 expression regulation in these cells.
\end{abstract}

\section{Introduction}

Matrix metalloproteinases (MMPs) are zinc depending endopeptidases involved in the modeling and remodeling of tissue.

Correspondence to: Dr Aurélie Trussardi-Régnier, Unité MEDyC CNRS UMR 6237, UFR Pharmacie, 1 avenue du Maréchal Juin 51100 Reims, France

E-mail: aurelie.trussardi@univ-reims.fr

Key words: proMMP-1, epigenetics, trichostatin A, 5-azadC
The degradation of Extra Cellular Matrix (ECM) macromolecules such as collagens, fibronectin, laminin, and proteoglycans by MMPs plays a crucial role in physiological and pathological processes (1). MMP-1 (collagenase-1) is the most ubiquitous interstitial collagenase and is able to initiate the breakdown of types I, II and III collagens (2,3). Matrix modeling by MMP-1 is considerably implicated in embryonic development, tissue morphogenesis and wound repair (4). Furthermore, MMP-1 overexpression is associated with several pathological conditions such as irreversible degradation of cartilage, tendon and bone in arthritis, and tumor invasion and metastasis (5-7). Transcriptional activation of proMMP-1 has been extensively studied, whereas the mechanisms involved in its expression remain largely unclear $(7,8)$.

Accumulating evidence highlights the important role of epigenetic mechanisms in the regulation of various genes that determine the biologic behavior of cells (9-11). DNA methylation and post-translational modifications of histones appear as two of the main mechanisms of chromatin remodeling regulating the accessibility of DNA to transcriptional machinery (12). DNA methylation/demethylation, which involves DNA methyltransferases (DNMTs) and demethylases, occurs on the C5 of cytosine in $\mathrm{CpG}$ islands often located in or near the promoter region of approximately $50 \%$ of genes. In malignancies, DNA methylation is frequently dysregulated. By interfering with the transcription initiation, the methylation of $\mathrm{CpG}$ islands inhibits gene expression and then represses suppressor tumor genes (13). The covalent modifications of the nucleosome core histones $\mathrm{H} 3, \mathrm{H} 4, \mathrm{H} 2 \mathrm{~A}$ and $\mathrm{H} 2 \mathrm{~B}$ consist in the addition on their $\mathrm{N}$ terminal tails of various groups (methyl, acetyl, phosphoryl, ubiquitin, etc). The most characterized modification is the acetylation/deacetylation catalyzed by the Histone Acetyl Transferases (HATs) and the Histone Deacetylases (HDACs). The transfer of acetyl group modifies the affinity between DNA and histones and then modulates chromatin condensation. Thereby, acetylation of histones may induce the activation of gene transcription (14). Furthermore, there is substantial evidence that a key link exists between cytosine methylation and post-translational modification of histones (15-17).

It has been established that the proMMP-1 gene expression requires chromatin remodeling in part via histone posttranslational modifications (18-22). A previous study showed that proMMP-1 gene expression induced by TPA in T98G cells involved a dynamic and ordered recruitment of enzymes 
allowing $\mathrm{H} 3 / \mathrm{H} 4$ acetylation, $\mathrm{H} 3 \mathrm{~K} 4$ di-and trimethylation, H3S10 phosphorylation and chromatin opening (22). Furthermore, it was shown that the production of MMP-1, in rheumatoid arthritis, is mediated by small ubiquitin-like modifier (SUMO) which triggers HDAC4 allowing histone hyperacetylation and gene expression $(20,21)$. However, the potential role of DNA methylation in the regulation of proMMP-1 expression remained unclear.

The aim of this study was therefore to analyze the effects of the inhibitor of DNA methylation 5-aza-2'-deoxycytidine (5-azadC) and the Histone Deacetylase Inhibitor (HDI) trichostatin A (TSA) on the proMMP-1 expression, both at the mRNA and protein levels. By using nuclear texture image, the relationships between higher-order chromatin supraorganization and proMMP-1 gene expression were also analyzed.

\section{Materials and methods}

Cell culture and treatment. Human fibrosarcoma HT1080 cells (ATCC, CCL-121) were grown at $37^{\circ} \mathrm{C}$ in RMPI medium supplemented with $10 \%$ fetal calf serum (FCS), $100 \mathrm{U} / \mathrm{ml}$ penicillin and $100 \mu \mathrm{g} / \mathrm{ml}$ streptomycin in a humidified $95 \%$ air, $5 \% \mathrm{CO}_{2}$ atmosphere. Before stimulation, cells were washed twice with PBS, and then incubated in serum-free medium for $24 \mathrm{~h}$. Cells were treated or not 2 or $5 \mu \mathrm{M}$ of 5-aza-2'-deoxycytidine $(5-\mathrm{azadC})$ and/or $100 \mathrm{ng} / \mathrm{ml}$ of trichostatin A (TSA) and/or $10 \mu \mathrm{g} / \mathrm{ml}$ of cycloheximide $(\mathrm{CHX})$ for the indicated times.

ProMMP-1 gene expression analysis. After stimulation, cells were washed twice in ice-cold PBS and total RNAs were isolated using TRIzol reagent (Invitrogen). For quantitative RT-PCR, $1 \mu \mathrm{g}$ of RNA was reverse transcribed using MMLV reverse transcriptase (Invitrogen), and each cDNA sample was analyzed by real-time PCR using Platinium SYBR Green qPCR SuperMix-UDG kit (Invitrogen) on the LightCycler system (Roche Diagnostics). ProMMP-1 transcripts were amplified using the following primers: proMMP-1 forward 5'-GAGCAAACACATCTGACCTACAGGA-3'; proMMP-1 reverse 5'-TTGTCCCGATGATCTCCCCTGACA-3'. Relative quantification was performed by using the housekeeping gene $\beta_{2}$ macroglobulin as a reference: $\beta_{2} m$ forward 5'-ATCTTCAA ACCTCCATGATG-3'; $\beta_{2} m$ reverse 5'-ACCCCCACTGAAAA AGATGA-3'.

ProMMP-1 Western blot analysis. Cells culture media were harvested and concentrated using Amicon Ultra centrifugal filters (Millipore). Total proteins $(35 \mu \mathrm{g})$ were heated $5 \mathrm{~min}$ at $100^{\circ} \mathrm{C}$ in Laemmli sample buffer, separated on $10 \%$ SDS PAGE under reducing conditions and transferred to PVDF membrane by using I-Blot system (Invitrogen). The membranes were placed in blocking solution [5\% (w/v) Blotto in TrisBuffered-Saline/Tween 20] for $2 \mathrm{~h}$ at room temperature and incubated overnight at $4^{\circ} \mathrm{C}$ with anti-MMP-1 (Mouse, Ab-1, Calbiochem/Merck, 1:1000) or anti- $\beta$-actin (Mouse, clone AC-15, Sigma Aldrich, 1:10000) primary antibodies. Proteins were revealed using a peroxydase-conjugated secondary antibody (Goat anti-mouse IgG, Millipore, 1:10000) and the ECL Plus detection kit (Amersham).
Histone extraction and immunoblotting. Histones were acid extracted with $\mathrm{HCl}$ and precipitated with aceton. Total histones $(15 \mu \mathrm{g})$ were separated on $15 \%$ SDS PAGE and transferred to PVDF membrane. The membranes were blocked during $2 \mathrm{~h}$ and incubated overnight with a primary antibody against acetylated total histone H4 (Rabbit, 06-866, Upstate, 1:2,000) and a peroxydase-conjugated anti rabbit secondary antibody (GE Healthcore, 1:100,000).

Image cytometry. Cells were grown and treated with TSA in LabTek chambered slides (Nunc). Cells were air-dried and fixed in alcohol-formalin mixture (95\% ethanol, 3\% formaldehyde in saline 3:1). After $5 \mathrm{~N} \mathrm{HCl}$ hydrolysis, slides were stained by the Feulgen method. Image cytometry was performed as described with an image analysis system (SAMBA 2005, Samba Technologies) coupled to a color 3CCD camera (XC-007P, Sony Corp. Japan) and a microscope (Axioscop, Karl Zeiss) (23). $G_{0} / G_{1}$ nuclei were extracted as previously reported (23). Nine texture parameters were computed from $\mathrm{G}_{0} / \mathrm{G}_{1}$ nuclei after reduction to 16 gray levels by linear rescaling. Four features were calculated on the gray levels co-occurrence matrix: local mean of gray levels (LM), energy (E), entropy (ENT), and inertia (I). Five parameters were calculated on the run-length matrix: short run-length emphasis (SRE), long run-length emphasis (LRE), gray level distribution (GLD), run-length distribution (RLD) and run-length percentage (RPC). The distribution, mean, and SD of the nuclear parameters were calculated for each cell population.

In order to perform multiple cell groups comparisons, a deviation index was calculated, by computing, for each parameter measured in a given nucleus, the difference in value to the feature value observed in control untreated nuclei (24). These differences are then standardized by dividing them by the corresponding standard deviations in the control cells data sets. Significance of the differences between indexes values was estimated by t-test after Bonferroni correction for multiple variables. Another data reduction method is computing an average nuclear abnormality index (NAI) which was calculated for each cell line as the arithmetic mean of the absolute values of the deviation indexes (z-scores) observed overall included features for all nuclei in a data set $(24,25)$.

Statistical analysis. All experiments were performed in triplicate. Results are expressed as mean \pm SEM. Statistical analysis was realized using Kruskal-Wallis test except otherwise specified. The results were considered significantly different when $\mathrm{p}<0.05$.

\section{Results}

Epigenetic modulation of proMMP-1 gene expression. In order to know whether DNA methylation mechanisms could be involved in proMMP-1 gene expression, fibrosarcoma HT1080 cells were treated with the DNA methylation inhibitor 5-azadC (2 or $5 \mu \mathrm{M})$ and/or the Histone Deacetylase Inhibitor (HDI) TSA (100 ng/ml) for various times. Levels of endogenous proMMP-1 mRNA were monitored by real-time RT-PCR. Compared to control cells, TSA induced histone $\mathrm{H} 4$ acetylation after $0.5 \mathrm{~h}$ of treatment but did not modulate proMMP-1 mRNA levels (Fig. 1A and B). After $48 \mathrm{~h}$ of treatment with 2 or 
A

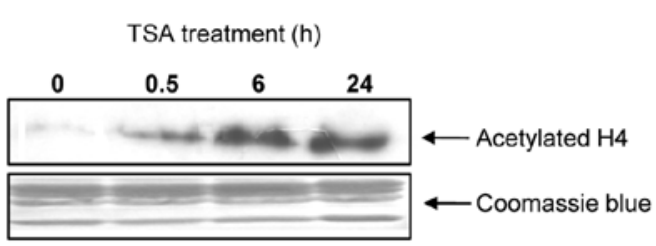

B

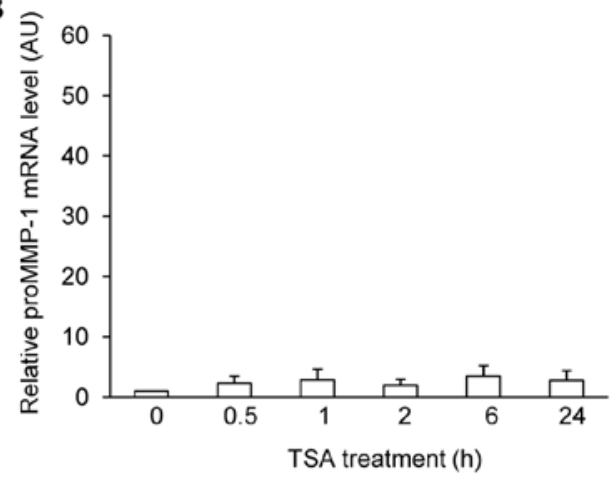

D

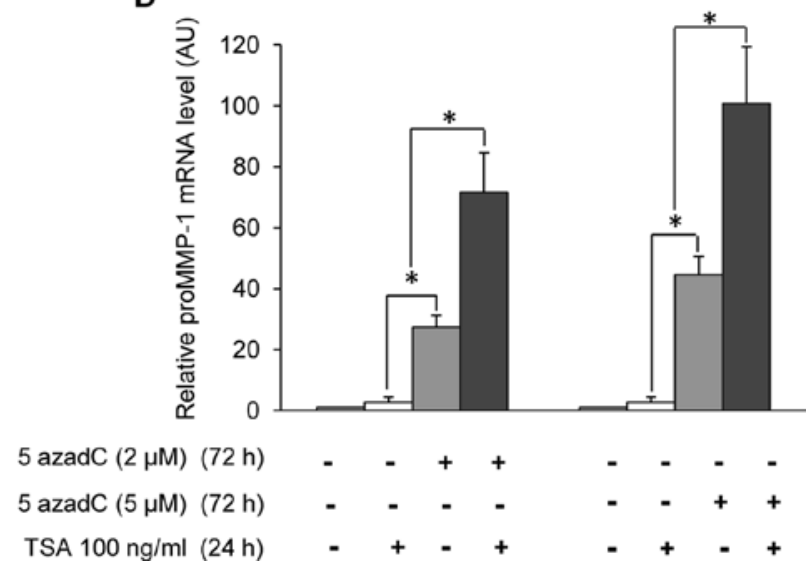

Figure 1. Effects of 5-azadC and TSA on proMMP-1 gene expression. HT1080 cells were treated or not with TSA (100 ng/ml), 5 -azadC ( 2 or $5 \mu \mathrm{M})$, or both drugs for various times as indicated on the figures. (A) Histones were acid extracted and Western blotting using total acetylated $\mathrm{H} 4$ histone antibody was performed. (B-D) Levels of endogenous mRNA were monitored by real-time RT-PCR. $\beta_{2}$ microglobulin $\left(\beta_{2} m\right)$ was used as internal control. Results are expressed as the mean \pm SEM of normalized ratio proMMP-1/ $\beta_{2} m$. $\mathrm{p}<0.05$ (Kruskal Wallis statistical test).

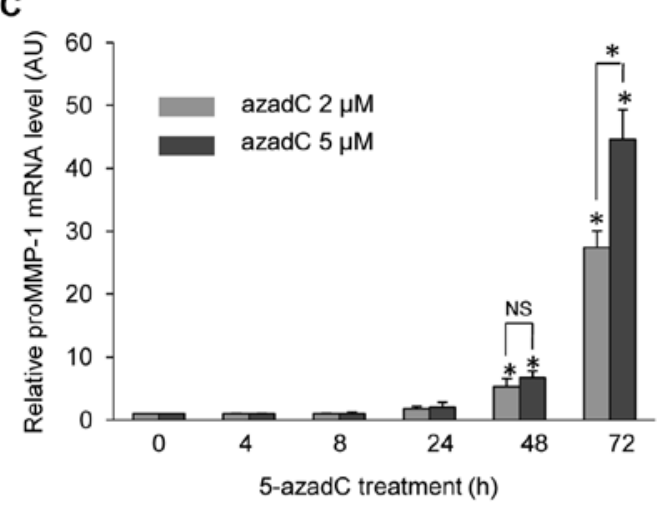

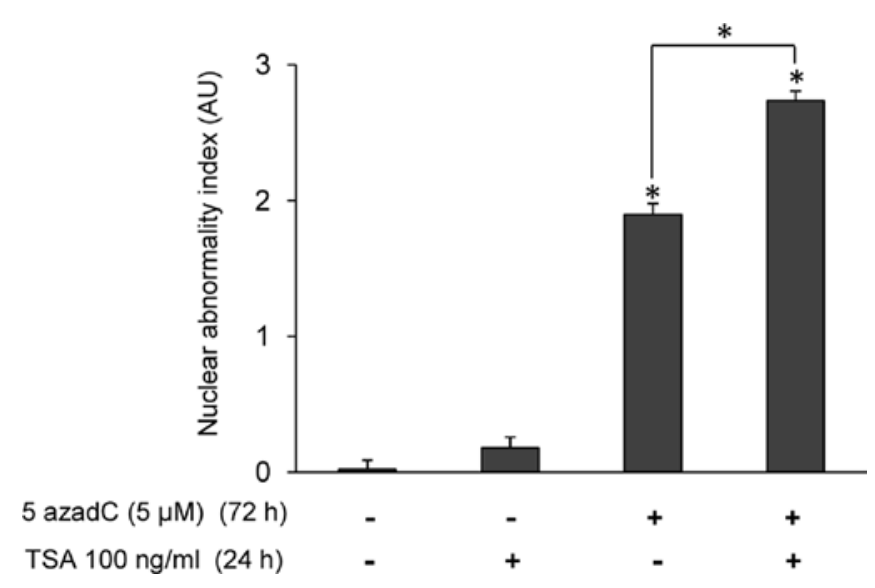

Figure 2. Effects of 5-azadC and TSA on chromatin supraorganization. HT1080 cells were treated or not with TSA (100 ng/ml 24 h) and/or 5-azadC $(5 \mu \mathrm{M} 72 \mathrm{~h})$. After Feulgen staining, 9 nuclear texture features were analyzed on $\mathrm{G}_{0} / \mathrm{G}_{1}$ nuclei using image cytometry. Results are expressed as nuclear abnormality index. " $\mathrm{p}<0.05$ (t-test after Bonferonni correction).

$5 \mu \mathrm{M}$ of 5 -azadC, proMMP-1 gene expression was increased (6-fold increased, $\mathrm{p}<0.05$ ). ProMMP-1 expression was further increased after $72 \mathrm{~h}$ of 5 -azadC treatment (30-fold increased with $2 \mu \mathrm{M} \mathrm{p}<0.05,45$-fold increased with $5 \mu \mathrm{M} \mathrm{p}<0.05)$ (Fig. 1C). When cells were simultaneously treated with TSA
$(100 \mathrm{ng} / \mathrm{ml} 24 \mathrm{~h})$ and 5 -azadC (2 or $5 \mu \mathrm{M} 72 \mathrm{~h})$, proMMP-1 was strongly expressed (70-fold increased with $2 \mu \mathrm{M}, 100$-fold increased with $5 \mu \mathrm{M}$ ) compared to 5 -azadC alone (Fig. 1D).

Nuclear texture. To examine the effects of these drugs on nuclear phenotype, image cytometry was performed on $\mathrm{G}_{0} / \mathrm{G}_{1}$ nuclei of HT1080 cells treated by TSA $(100 \mathrm{ng} / \mathrm{ml} 24 \mathrm{~h})$ and/ or 5-azadC (5 $\mu \mathrm{M} 72 \mathrm{~h})$. As shown in Fig. 2, these treatments induced significant chromatin higher-order organization changes, as evaluated by NAI computing. Moreover, simultaneous treatments with 5-azadC and TSA resulted in a synergistic effect on nuclear phenotypic alterations. In 5-azadC treated cells, analysis of individual deviation indexes (Table I) revealed that these changes corresponded to a global chromatin decondensation, as evidenced by a decrease in LM, with a less compact (increase in E, decreases in ENT and I) and more homogeneously and finely distributed chromatin (decreases in SRE and RPC, increases in LRE and GLD). The intensity of these changes was further increased by TSA addition. On the other hand, TSA alone induced a very slight but significant decompaction of chromatin (increase in E) which appeared containing reduced heterochromatin areas (increase in LRE, decrease in RPC).

Analysis of proMMP-1 secretion. To correlate gene expression with protein secretion after treatment by epigenetic modulators, Western blot analysis was performed on cell conditioned media. 


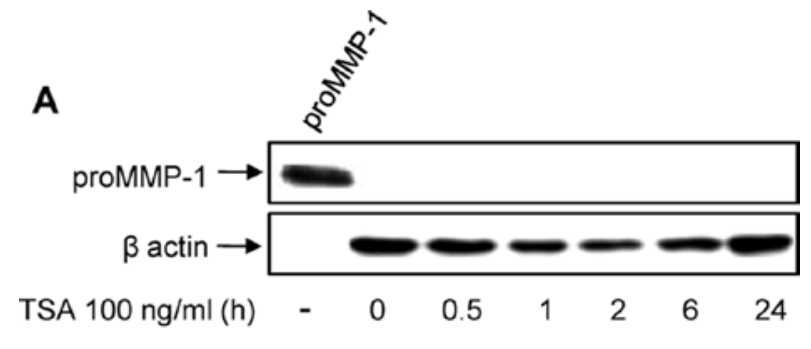

B

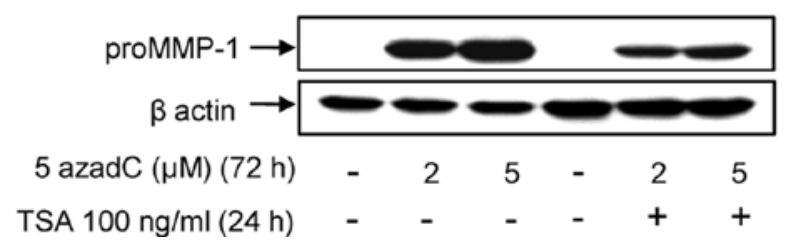

Figure 3. Effects of 5-azadC and TSA on proMMP-1 secretion. HT1080 cells were treated or not with TSA and/or 5-azadC as indicated on the figures. (A and B) Western blot analyses of cell concentrated conditioned media: $35 \mu \mathrm{g}$ of total proteins were analyzed. Panel A (lane 1), recombinant proMMP-1 was used as positive control.
Table I. Values of deviation indexes in 5-azadC and TSA treated HT1080 cell nuclei.

\begin{tabular}{lccr}
\hline \multicolumn{3}{c}{ Treatments } \\
\hline Parameters & TSA & 5 -azadC & 5 -azadC + TSA \\
\hline LM & $-0.09 \pm 0.06$ & $-1.94 \pm 0.03^{\mathrm{a}}$ & $-2.17 \pm 0.02^{\mathrm{a}, \mathrm{b}}$ \\
E & $0.21 \pm 0.05$ & $2.81 \pm 0.08^{\mathrm{a}}$ & $4.36 \pm 0.13^{\mathrm{a}, \mathrm{b}}$ \\
ENT & $-0.13 \pm 0.05$ & $-2.19 \pm 0.04^{\mathrm{a}}$ & $-2.84 \pm 0.04^{\mathrm{a}, \mathrm{b}}$ \\
I & $-0.14 \pm 0.06$ & $-1.26 \pm 0.04^{\mathrm{a}}$ & $-1.68 \pm 0.02^{\mathrm{a}, \mathrm{b}}$ \\
SRE & $-0.14 \pm 0.06$ & $-1.42 \pm 0.02^{\mathrm{a}}$ & $-1.96 \pm 0.02^{\mathrm{a}, \mathrm{b}}$ \\
LRE & $0.46 \pm 0.06^{\mathrm{a}}$ & $1.84 \pm 0.05^{\mathrm{a}}$ & $3.74 \pm 0.10^{\mathrm{a}, \mathrm{b}}$ \\
GLD & $0.02 \pm 0.05$ & $2.64 \pm 0.06^{\mathrm{a}}$ & $3.64 \pm 0.08^{\mathrm{a}, \mathrm{b}}$ \\
RLD & $-0.13 \pm 0.06$ & $-1.40 \pm 0.02^{\mathrm{a}}$ & $-1.90 \pm 0.02^{\mathrm{a}, \mathrm{b}}$ \\
RPC & $-0.29 \pm 0.05^{\mathrm{a}}$ & $-1.58 \pm 0.03^{\mathrm{a}}$ & $-2.34 \pm 0.03^{\mathrm{a}, \mathrm{b}}$ \\
\hline
\end{tabular}

Values are expressed as mean \pm SEM. ${ }^{\mathrm{a}} \mathrm{p}<0.05$ as compared to control untreated cells ( $\mathrm{t}$-test after Bonferroni correction). ${ }^{\mathrm{b}} \mathrm{p}<0.05$ as compared to 5-azadC alone (t-test after Bonferroni correction).
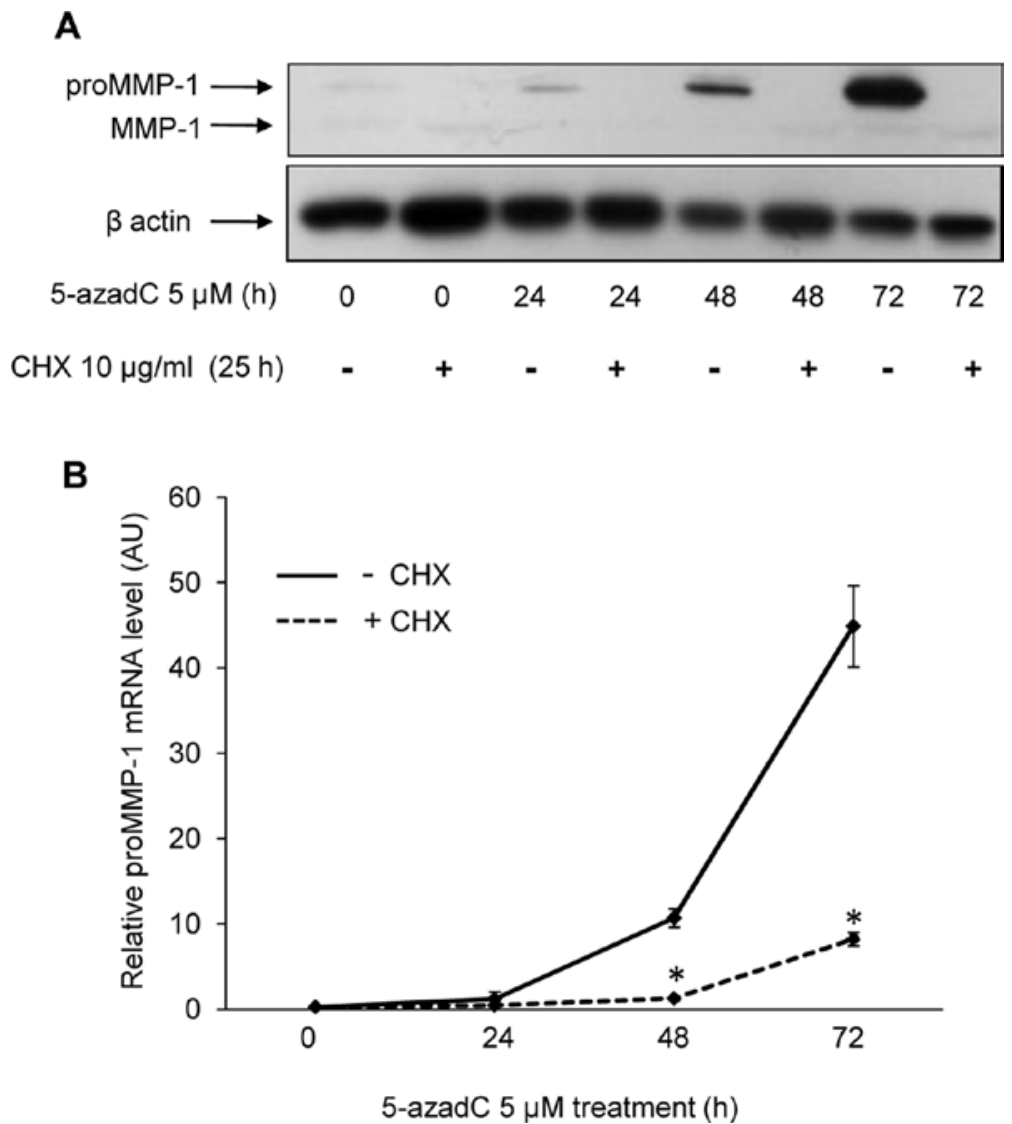

Figure 4. Effect of protein neosynthesis inhibition on proMMP-1 mRNA and protein levels. HT1080 cells were treated or not with 5-azadC and/or CHX as indicated in the figures. (A) Western blot analysis of cell-concentrated conditioned media: $35 \mu \mathrm{g}$ of total proteins were analyzed. (B) Real-time RT-PCR of proMMP-1 mRNA. $\beta_{2}$ microglobulin $\left(\beta_{2} m\right)$ was used as internal control. Results are expressed as the mean $\pm \mathrm{SEM}$ of normalized ratio proMMP-1/ $\beta_{2} m$. ${ }^{*} \mathrm{p}<0.05$ as compared to $\mathrm{CHX}$ untreated cells values (Kruskal Wallis statistical test).

The results show that TSA alone did not induce proMMP-1 secretion (Fig. 3A). 5-azadC or 5-azadC and TSA induced proMMP-1 secretion in supernatants (Fig. 3B). However, the association of both drugs induced a weaker secretion than 5 -azadC alone.
Indirect epigenetic regulation of proMMP-1 expression. Despite its induction by 5-azadC, proMMP-1 gene does not contain $\mathrm{CpG}$ islands. In order to investigate if other intermediate molecules could be involved in the regulation of proMMP-1 
expression, the neosynthesis of proteins was blocked with cycloheximide (CHX). HT1080 were treated or not with 5-azadC $(5 \mu \mathrm{M} 72 \mathrm{~h})$ and $\mathrm{CHX}(10 \mu \mathrm{g} / \mathrm{ml} 25 \mathrm{~h})$. CHX totally abolished proMMP-1 secretion induced by 5 -azadC, thus confirming the efficiency of the CHX treatment (Fig. 4A), and reduced strongly proMMP-1 mRNA levels up to $72 \mathrm{~h}$ (Fig. 4B).

\section{Discussion}

In most tumor cells, proMMP-1 mRNA levels are very low but can be induced by a wide variety of stimuli (7,8,26-28). For instance, interleukin-1 $\beta$, UV radiations or phorbol esters, increase proMMP-1 gene expression through histone posttranslational modifications $(22,29)$. In this study we observed that accumulation of hyperacetylated histones is not a sufficient trigger to enhance either proMMP-1 gene expression or chromatin global decondensation in HT1080 fibrosarcoma cells. Similarly, it was previously reported that an increase in histone acetylation level, induced by HDI treatment, did not seem to have any effect on unstimulated levels of $M M P S$ whereas it could enhance already stimulated $M M P$ production (30). This suggests that HDI effects could target the signaling pathways induced by exogenous stimuli (e.g., inflammatory cytokines, growth factors and phorbol esters) rather than the proMMP-1 gene itself.

These histone post-translational modifications are only one possible mechanism and accumulating evidence supports epigenetic cross-talk between DNA methylation and histone modifications in the regulation of gene expression (31). During this cross-talk, DNA methylation appears to be the initial signal that triggers events leading to non-permissive chromatin. In HT1080 cells, we showed that a treatment with the DNA demethylating agent 5-azadC induced a global chromatin decondensation and an increase in proMMP-1 expression. Interestingly, this gene promoter, unlike other $M M P s$, does not appear to contain CpG islands (32), suggesting that 5-azadC effects occur via either demethylation of other genes, or different mechanisms (33). Moreover, histone hyperacetylation by TSA activates proMMP-1 expression only after chromatin demethylation and both epigenetic mechanisms display synergistic effects on gene expression and nuclear architecture alteration. These ordered re-expression and synergy, involving DNMTs, MBDs and HDACs $(16,34)$, have been reported with other genes (35-38), but not concerning the proMMP-1 gene.

The simultaneous treatment with TSA increased proMMP-1 mRNA levels, but surprisingly, decreased MMP-1 protein secretion. Such a TSA-induced decrease in MMP-1 secretion was also observed in mesenchymal cells treated with IL-1 $\beta$ (30). Post-transcriptional regulatory processes including mRNA stability, protein translational efficiency, and microRNA-based mechanisms have been recently described as modulators of MMPs expression (39). Several non-histone proteins have been identified as acetylation targets and hyperacetylation of these proteins could play important roles in the mRNA stability regulation, protein localization and degradation, and protein-protein and protein-DNA interactions. HDI treatment may thus destabilize mRNA and decrease the resulting protein level, as reported here for proMMP-1 $(40,41)$. Indeed the $M M P$ mRNA transcripts harbor specific sequences in their $5^{\prime}$ or $3^{\prime}$ untranslated regions
(UTRs) which are potential targets of regulatory proteins involved in mRNA stability (39). On the other hand, HDI treatment may activate miRNA expression and modulate tumor cell invasiveness (42-45). For instance, miR22 was shown to be upregulated by TSA treatment but not by 5 -azadC (42). Target sequence analyses revealed that this TSA-inducible miRNA could target and potentially repress proMMP-1 expression. Therefore it could play, as many other miRNAs, a significant role in the regulation of proMMP-1 expression (43).

Finally, inhibition of protein neosynthesis abolishes the 5-azadC-induced proMMP-1 mRNA increase, a phenomenon not observed for MMP-2 or MMP-9 genes (data not shown). These data suggest that some intermediary molecules could be involved in the regulation of proMMP-1 gene expression and that their production could be specifically triggered by DNA demethylation. For instance, proMMP-1 expression could be mediated by autocrine mechanisms (46) involving cytokines and growth factors (7) whose expression in HT1080 cells could be upregulated by 5 -azadC.

Identification of such proMMP-1 inducers could therefore shed new light on the impact of epigenetic regulation on invasive properties of cancer cells.

\section{Acknowledgements}

This study was supported by grants from the Comité Départemental de l'Aube de la Ligue Nationale Contre le Cancer.

\section{References}

1. Kessenbrock K, Plaks V and Werb Z: Matrix metalloproteinases: regulators of the tumor microenvironment. Cell 141: 52-67, 2010.

2. Brinckerhoff CE: Regulation of collagenase gene expression in synovial cells. J Rheumatol 14 Spec: 61-63, 1987.

3. Saffarian S, Collier IE, Marmer BL, Elson EL and Goldberg G: Interstitial collagenase is a Brownian ratchet driven by proteolysis of collagen. Science 306: 108-111, 2004.

4. Sternlicht MD and Werb Z: How matrix metalloproteinases regulate cell behavior. Annu Rev Cell Dev Biol 17: 463-516, 2001.

5. Lu X, Wang Q, Hu G, et al: ADAMTS1 and MMP1 proteolytically engage EGF-like ligands in an osteolytic signaling cascade for bone metastasis. Genes Dev 23: 1882-1894, 2009.

6. Sauter W, Rosenberger A, Beckmann L, et al: Matrix metalloproteinase 1 (MMP1) is associated with early-onset lung cancer. Cancer Epidemiol Biomarkers Prev 17: 1127-1135, 2008.

7. Vincenti MP, White LA, Schroen DJ, Benbow U and Brinckerhoff CE: Regulating expression of the gene for matrix metalloproteinase-1 (collagenase): mechanisms that control enzyme activity, transcription, and mRNA stability. Crit Rev Eukaryot Gene Expr 6: 391-411, 1996.

8. Vincenti MP, Coon CI, Lee O and Brinckerhoff CE: Regulation of collagenase gene expression by IL-1 beta requires transcriptional and post-transcriptional mechanisms. Nucleic Acids Res 22: 4818-4827, 1994

9. Jones PA: Epigenetics in carcinogenesis and cancer prevention. Ann N Y Acad Sci 983: 213-219, 2003.

10. Jones PA and Baylin SB: The epigenomics of cancer. Cell 128: 683-692, 2007.

11. Wang X, Song Y, Jacobi JL and Tuan RS: Inhibition of histone deacetylases antagonized FGF2 and IL-1beta effects on MMP expression in human articular chondrocytes. Growth Factors 27: 40-49, 2009.

12. Delcuve GP, Rastegar M and Davie JR: Epigenetic control. J Cell Physiol 219: 243-250, 2009.

13. Esteller M: Cancer epigenetics: DNA methylation and chromatin alterations in human cancer. Adv Exp Med Biol 532: 39-49, 2003. 
14. Wang GG, Allis CD and Chi P: Chromatin remodeling and cancer, Part I: Covalent histone modifications. Trends Mol Med 13: 363-372, 2007.

15. Cervoni N, Detich N, Seo SB, Chakravarti D and Szyf M: The oncoprotein Set/TAF-1beta, an inhibitor of histone acetyltransferase, inhibits active demethylation of DNA, integrating DNA methylation and transcriptional silencing. J Biol Chem 277: 25026-25031, 2002

16. Fuks F, Hurd PJ, Deplus R and Kouzarides T: The DNA methyltransferases associate with HP1 and the SUV39H1 histone methyltransferase. Nucleic Acids Res 31: 2305-2312, 2003.

17. Jones PL, Veenstra GJ, Wade PA, et al: Methylated DNA and $\mathrm{MeCP} 2$ recruit histone deacetylase to repress transcription. Nat Genet 19: 187-191, 1998.

18. Chernov AV, Baranovskaya S, Golubkov VS, et al: Microarraybased transcriptional and epigenetic profiling of matrix metalloproteinases, collagens, and related genes in cancer. J Biol Chem 285: 19647-19659, 2010.

19. Kim MK, Shin JM, Eun HC and Chung JH: The role of p300 histone acetyltransferase in UV-induced histone modifications and MMP-1 gene transcription. PLoS One 4: E4864, 2009.

20. Kirsh O, Seeler JS, Pichler A, et al: The SUMO E3 ligase RanBP2 promotes modification of the HDAC4 deacetylase. EMBO J 21: 2682-2691, 2002.

21. Maciejewska-Rodrigues H, Karouzakis E, Strietholt S, et al: Epigenetics and rheumatoid arthritis: the role of SENP1 in the regulation of MMP-1 expression. J Autoimmun 35: 15-22, 2010.

22. Martens JH, Verlaan M, Kalkhoven E and Zantema A: Cascade of distinct histone modifications during collagenase gene activation. Mol Cell Biol 23: 1808-1816, 2003.

23. Dufer J, Millot-Broglio C, Oum'Hamed Z, et al: Nuclear DNA content and chromatin texture in multidrug-resistant human leukemic cell lines. Int J Cancer 60: 108-114, 1995.

24. Bartels PH, da Silva VD, Montironi R, et al: Chromatin texture signatures in nuclei from prostate lesions. Anal Quant Cytol Histol 20: 407-416, 1998.

25. Montironi R, Scarpelli M, Mazzucchelli R, et al: Subvisual changes in chromatin organization state are detected by karyometry in the histologically normal urothelium in patients with synchronous papillary carcinoma. Hum Pathol 34: 893-901, 2003.

26. Armstrong DA, Phelps LN and Vincenti MP: CCAAT enhancer binding protein-beta regulates matrix metalloproteinase-1 expression in interleukin-1beta-stimulated A549 lung carcinoma cells. Mol Cancer Res 7: 1517-1524, 2009.

27. Cortez DM, Feldman MD, Mummidi S, et al: IL-17 stimulates MMP-1 expression in primary human cardiac fibroblasts via p38 MAPK- and ERK1/2-dependent C/EBP-beta, NF-kappaB, and AP-1 activation. Am J Physiol Heart Circ Physiol 293: H3356-H3365, 2007.

28. Delany AM and Brinckerhoff CE: Post-transcriptional regulation of collagenase and stromelysin gene expression by epidermal growth factor and dexamethasone in cultured human fibroblasts. J Cell Biochem 50: 400-410, 1992.

29. Burrage PS, Huntington JT, Sporn MB and Brinckerhoff CE: Regulation of matrix metalloproteinase gene expression by a retinoid X receptor-specific ligand. Arthritis Rheum 56: 892-904 2007.

30. Pender SL, Quinn JJ, Sanderson IR and MacDonald TT: Butyrate upregulates stromelysin-1 production by intestinal mesenchymal cells. Am J Physiol Gastrointest Liver Physiol 279: G918-G924, 2000
31. Vaissiere T, Sawan C and Herceg Z: Epigenetic interplay between histone modifications and DNA methylation in gene silencing. Mutat Res 659: 40-48, 2008.

32. Clark IM, Swingler TE, Sampieri CL and Edwards DR: The regulation of matrix metalloproteinases and their inhibitors. Int J Biochem Cell Biol 40: 1362-1378, 2008.

33. Momparler RL: Pharmacology of 5-Aza-2'-deoxycytidine (decitabine). Semin Hematol 42: S9-S16, 2005.

34. Bogdanovic O and Veenstra GJ: DNA methylation and methyl$\mathrm{CpG}$ binding proteins: developmental requirements and function. Chromosoma 118: 549-565, 2009.

35. Cameron EE, Bachman KE, Myohanen S, Herman JG and Baylin SB: Synergy of demethylation and histone deacetylase inhibition in the re-expression of genes silenced in cancer. Nat Genet 21: 103-107, 1999.

36. El-Osta A, Kantharidis P, Zalcberg JR and Wolffe AP: Precipitous release of methyl- $\mathrm{CpG}$ binding protein 2 and histone deacetylase 1 from the methylated human multidrug resistance gene (MDR1) on activation. Mol Cell Biol 22: 1844-1857, 2002.

37. Meng CF, Zhu XJ, Peng G and Dai DQ: Re-expression of methylation-induced tumor suppressor gene silencing is associated with the state of histone modification in gastric cancer cell lines. World J Gastroenterol 13: 6166-6171, 2007.

38. Si J, Boumber YA, Shu J, et al: Chromatin remodeling is required for gene reactivation after decitabine-mediated DNA hypomethylation. Cancer Res 70: 6968-6977, 2010.

39. Fanjul-Fernandez M, Folgueras AR, Cabrera S and Lopez-Otin C: Matrix metalloproteinases: evolution, gene regulation and functional analysis in mouse models. Biochim Biophys Acta 1803: 3-19, 2010.

40. Singh BN, Zhang G, Hwa YL, Li J, Dowdy SC and Jiang SW: Non histone protein acetylation as cancer therapy targets. Expert Rev Anticancer Ther 10: 935-954, 2010.

41. Zhou Q, Shaw PG and Davidson NE: Inhibition of histone deacetylase suppresses EGF signaling pathways by destabilizing EGFR mRNA in ER-negative human breast cancer cells. Breast Cancer Res Treat 117: 443-451, 2009.

42. Li X, Liu J, Zhou R, Huang S, Huang S and Chen XM: Gene silencing of MIR22 in acute lymphoblastic leukaemia involves histone modifications independent of promoter DNA methylation. Br J Haematol 148: 69-79, 2010.

43. Liu X, Yu J, Jiang L, et al: MicroRNA-222 regulates cell invasion by targeting matrix metalloproteinase 1 (MMP1) and manganese superoxide dismutase 2 (SOD2) in tongue squamous cell carcinoma cell lines. Cancer Genomics Proteomics 6: 131-139, 2009.

44. Pang RT, Leung CO, Ye TM, et al: MicroRNA-34a suppresses invasion through downregulation of Notch1 and Jagged1 in cervical carcinoma and choriocarcinoma cells. Carcinogenesis 31: 1037-1044, 2010

45. Zhang S, Cai X, Huang F, Zhong W and Yu Z: Effect of trichostatin a on viability and microRNA expression in human pancreatic cancer cell line BxPC-3. Exp Oncol 30: 265-268, 2008.

46. Vielhaber G, Grether-Beck S, Koch O, Johncock W and Krutmann J: Sunscreens with an absorption maximum of $>$ or $=360 \mathrm{~nm}$ provide optimal protection against UVA1-induced expression of matrix metalloproteinase-1, interleukin-1, and interleukin-6 in human dermal fibroblasts. Photochem Photobiol Sci 5: 275-282, 2006. 